\title{
Innovate! Integrate! Communicate!
}

By Steve Harmon, Georgia State University,

AECT President-elect

Anaheim, California

October 28-November 2, 2013

\author{
Concurrent Sessions: October 29- November 2 \\ Workshop Sessions: Tuesday, October 29 \\ Wednesday, October 30 \\ Saturday, November 2
}

$\mathbf{T}$ he 2013 annual convention in Anaheim California is shaping up to be one of the best ever. The call for proposals has now closed and reviewers are hard at work putting together the conference program. The conference will be held from October 30 to November 2 at the Hyatt Regency, Orange County. We have held the convention here a few times over the last several years, and those of you who have attended know that it is a wonderful location for a professional meeting. It offers 65,000 square feet of convention space with state-of- the-art meeting facilities. The hotel is just a few blocks from Disneyland and within easy access of the beach. The area offers a rich variety of dining and shopping options with multiple choices for virtually every taste and budget. The Anaheim GardenWalk is only 2 miles away and the Discovery Science Center just a bit further.

But you'll have to plan carefully to enjoy the many amenities surrounding the convention site, because the conference itself is sure to grab your attention and not let go. The members of AECT are the best research-



ers working in educational technology and some of the best presenters on the planet. Perhaps it's because of our common interest in visual and information design. At any AECT conference you will find a keynote level presentation going on in a small conference room at any time. First timers to the convention are often struck by the high level of professionalism that our presenters exhibit. So start making your plans now to attend the 2013 conference. Join the world-class conversation on the future of learning and technology. 